\title{
Escape to Sociality! Evaluation of the Relationship between Fitness Club members' Escape, Sociability, Friendship and Place Loyalty Structures with Their Loyalty Levels
}

\author{
CANER OZGEN ${ }^{1}$, HUSEYIN KOSE ${ }^{1}$, SERVET REYHAN ${ }^{2}$ \\ ${ }^{1}$ Eskisehir Technical University, Dept. of Sport Management \\ ${ }^{2}$ Siirt University, Dept. of Sport Management \\ Correspondence to Dr. Servet Reyhan, Email. servet.reyhan@siirt.edu.tr, Cell: +905426843331
}

\begin{abstract}
Background: In sports marketing literature, the importance of loyalty phenomenon has been emphasized many times. In the literature review, it has been determined that there are limited number of studies on motivational factors that affect the loyalty of fitness club members.

Aim: So, the purpose of the current research is to test empirically the factors that affect fitness club members loyalty

Methods: For this purpose, data obtained from a total of 652 fitness club members were analyzed in line with the methodological principles of SEM modelling.

Results: In the scope of the research it has been determined that sociability, escape, friend attachment and place attachment and WOM behaviors are directly or indirectly effect the loyalty of fitness club members. Based on these findings, both the theoretical and practical results of this research are discussed in the research.

Conclusion: The results of the research show that the marketers should understand the important role of factors such as social escape, friend and place attachment and they should act accordingly.

Keywords: Escape, fitness club, loyalty, place attachment.
\end{abstract}

\section{INTRODUCTION}

The sports industry, which is growing day by day, has reached volumes of billions of dollars today. In the wake of the concept of professionalization in sports, monetary issues have come to the forefront in sports clubs (Yavuz Eroglu and Eroglu (2020). ET his has made it necessary to conduct extensive academic research on sports and the economic aspects of sport. International Health, Racquet and Sports Club Association (IHRSA) has undertaken many studies that have found that one of the biggest growths in the sports industry is taking place in fitness clubs. Fitness halls, which create important changes especially in leisure habits, have become not only sports places but also important recreation centers for socializing, escaping the stress of daily life and interacting with people. This has led to a significant increase in the number of fitness clubs and thus the number of members.

Schiffman et al (2001) revealed that consumption, including service products, is driven by the tension created by absence ${ }^{1}$. Since motivation is a hypothetical structure, it is necessary to research the motives in the relevant area in order to measure and define motives. Funk et al. (2003) identified a number of basic and contextual motives related to the behavioral loyalty of sports consumers in their research ${ }^{2}$. It is thought that sociality, friend attachment and escape factors within the structure put forward may be important in understanding the consumption behaviors of fitness club members. Manzo (2003) stated that many studies in the field of recreation and leisure research investigate the nature of the emotional relationships of individuals with a number of places ${ }^{3}$. Place attachment is defined as the emotional bond between and individual and a specific environment ${ }^{4}$. In the developing literature on different disciplines, it has been determined that place attachment affects consumer loyalty ${ }^{5}$. Williams andVaske (2003) stated that the relationship between place attachment and loyalty should be investigated in different areas $^{6}$.

In parallel with this information, the aim of the research is to develop and test a conceptual model for the factors that affect consumer loyalty in fitness clubs. Particularly, the aim of the research is to provide empirical evidence to the gap previously mentioned in the relevant literature. The research is structured in three main parts in terms of the purposes of the research. First, a conceptual model has been developed in the context of the relevant literature. Within the proposed model, research hypotheses were analyzed in accordance with the methodological principles of SEM (Structural Equation Modeling). The determined results are discussed in detail in the context of current literature.

Hypotheses related to the research model: Segrave (2000) stated that one of the sources of contemporary appeal of sports is an escape from the confusion of daily life $^{7}$. Sports offers individuals one of the most important ways to enrich their socio-psychological lives ${ }^{8}$. Especially modern urban life causes individuals to think sport as in important tool for sociability, friendship and escape. Gau and Korzenny (2009) stated that individuals see sports as an important opportunity to meet social needs and spend time with others ${ }^{9}$. In line with all this information, the first three hypotheses of this research are as follows.

$\mathrm{H} 1$ There is a relationship between fitness club members' friend attachment and escape from the stress of daily life.

$\mathrm{H} 2$ There is a relationship between fitness club members' friend attachment and their sociability.

H3 There is a relationship between fitness club members' escape from the stress of daily life and their sociability.

Various perspectives have been developed regarding the place attachment, which is the subject of many 
researches in different disciplines. In general terms, Milligan (1998) stated that individuals associating social interactions occurring in a physical space with a place will create place attachment ${ }^{10}$. Researches Hidalgo and Hernández (2001) reveal that place attachment generally occurs related to the relationships shared with the social environment of individuals ${ }^{11}$.

$\mathrm{H} 4$ There is a relationship between fitness club members' sociability and place attachment.

There are similar studies in the literature about relationship assumption between WOM behavior and place attachment. Harrison-Walker (2001) found that loyalty had a positive impact on WOM $^{12}$. Bergami and Bagozzi (2000) found that the attachment between the employer and the staff has a positive effect on WOM behavior ${ }^{13}$. The findings obtained from different contexts reveal that there may be a relationship between place attachment and positive WOM behavior in fitness clubs. In line with this information, the fifth hypothesis of this research is as follows.

$\mathrm{H} 5$ There is a relationship between fitness club members' place attachment and WOM behavior.

The discovery of the relationships between individual and individual, individual and community and individual and place is very important in conceptualizing attachment in the context of the relevant discipline ${ }^{14}$. Many studies have been conducted in the sports science literature ${ }^{15}$, which confirm the positive relationship between identity and loyalty. This suggests that there may be a positive relationship between place attachment and behavioral loyalty. In line with this information, the sixth hypothesis of this research was created as follows.

H6 There is a relationship between fitness club members' place attachment and behavioral loyalty.

Behavioral loyalty is usually measured by purchasing behavior and does not provide information about the attitude of the consumer. It can be stated that the behavioral loyalty structure is inadequate in determining the future behavior of consumers. Behavioral intentions are the results of the socialization process. In this sense, WOM behavior is an important dimension related to the positive attitudes of consumers towards positive product or service. While people often rely on the opinions of others who are thought to have no vested interests, WOM is an important platform for influencing their behavior. Current studies show that WOM plays a satisfying role in influencing consumers' purchasing decisions and loyalty behavior ${ }^{17}$. These results revealed in the literature suggest that there may be a relationship between loyalty and WOM behavior in the context of this research. In line with this information, the seventh hypothesis of the research is formed as follows.

$\mathrm{H} 7$ There is a relationship between fitness club members' WOM behavior and behavioral loyalty.

\section{MATERIAL \& METHODS}

Data collection and sampling: Within the scope of the research, a total of 652 fitness club members were reached through convenience sampling method. The questionnaire form was presented by researchers to the opinions of 3 fitness center members operating in the city of Eskişehir, Turkey. Participants were given extensive information for the purposes of the research and no questionnaire was distributed to members who did not want to participate in the research. A total of 674 questionnaires were collected and 22 questionnaires were excluded due to incomplete and undisciplined coding. Accordingly, it was observed that the sample of the research scope was formed similar to the general population of the fitness club.

It was determined that a large part of the research participants was male (73.6\%) and they were between the ages of $18-25(72.1 \%)$. In addition, it was revealed that a significant part of the participants were university graduates $(57 \%)$ and single (79.2) individuals. Finally, it was determined in the scope of the research that the individuals who participated in the research were $53.1 \%$ and were going to fitness clubs 3-5 times in a week.

Measuring instruments: In the research, the questionnaire form consists of two parts. The first part included items on a five-point Likert scale (5-Strongly Agree; 1-Strongly Disagree) measuring instrument to be used for the study purposes. The second part were developed to determine the demographic variables of the participants. To identify fitness center members' attitudes toward escape, sociability and friend attachment, the items of the measuring instrument developed by Neale and Funk (2006) were used ${ }^{17}$. In order to determine the behavior of members' place attachment and WOM behavior, the items of the scale developed by Lee et al. (2012) ${ }^{18}$. Besides, the statements of the scale created by Prayag and Ryan (2012) were used to determine the loyalty levels of the participants ${ }^{5}$.

\section{RESULTS}

Measurement model: Six structures (friend attachment, sociability, escape, place attachment, WOM and behavioral loyalty) that form the research context were analyzed within the measurement model of the SEM procedure. CFA (confirmatory factor analysis) showed that the fit indices determined as a result are above the limits expressed in the literature $(X 2=228,440 \quad p=0,000, X 2 / S D=1,904$, $\mathrm{GFI}=0,93, \mathrm{AGFI}=0,90, \mathrm{CFI}=0,92, \mathrm{TLI}=0,91, \mathrm{IFI}=0,92$, RMSEA =0,051).

AVE values of all structures were calculated to determine the compatibility validity of all dimensions of the model within the scope of the measurement model, and all values were found to be above 0.50. In addition, Cronbach's alpha and CR (Composite Reliability) coefficients were calculated to determine the reliability levels of the structures included in the research and it was determined that they are far above the limits (Table 1). For the external validity of the measurement model, the relationships of all structures were examined, and the correlation coefficients were statistically significant, but all the coefficients were below 0.85. In line with this information, it can be stated that the measurement model used in the research is a valid and reliable model. 
Table 1: Structures related to measurement model and statements about structures

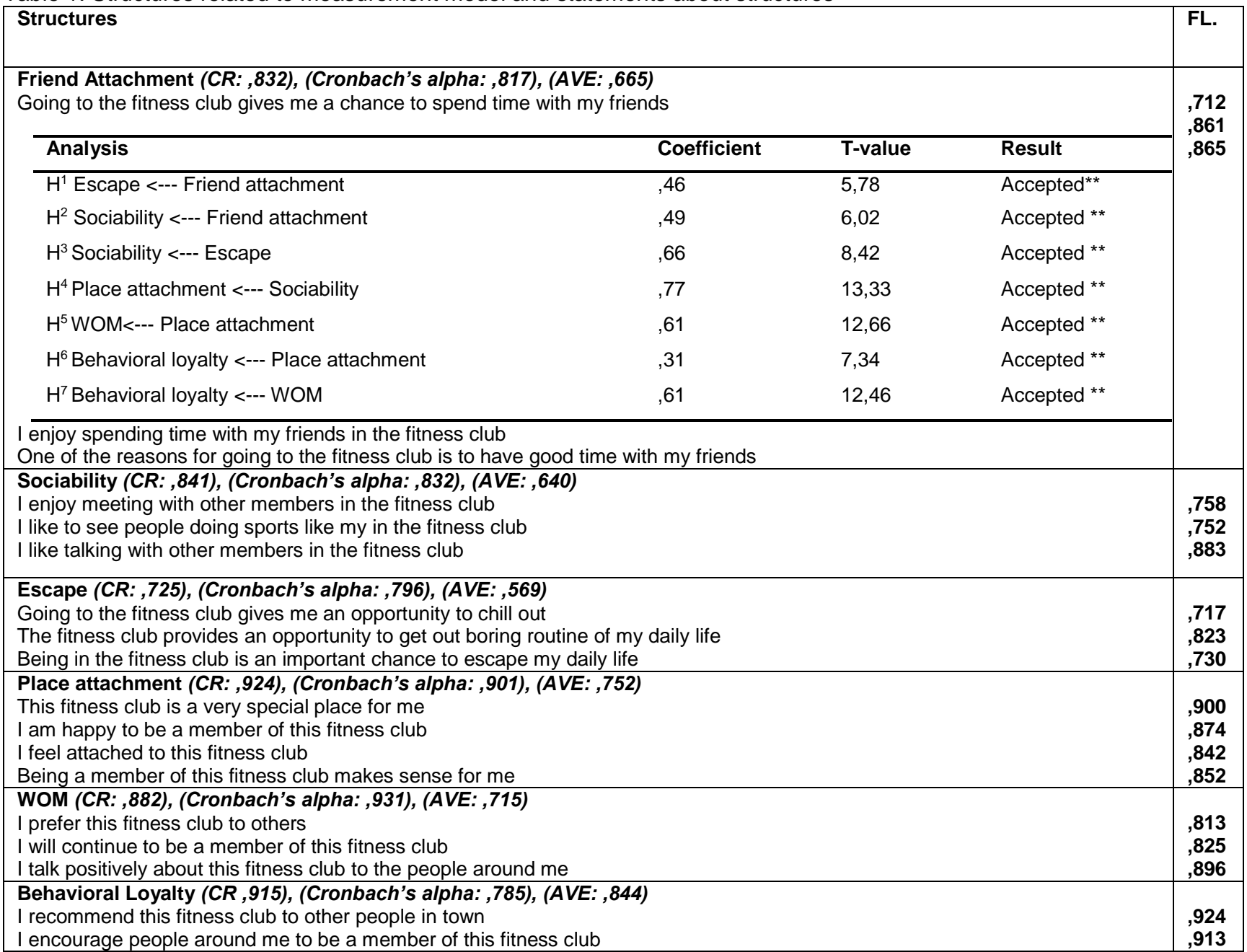

FL: Factor Loading, CR: Composite Reliability, AVE: Average Variance Extracted

Structural model: After verification of the measurement model created within the scope of the research, the hypotheses were tested within the scope of the structural model, the second phase of the SEM procedure As a result of the analysis, it has been revealed that the model has acceptable goodness of fit values. $(X 2=502,183 p=0,000, X 2 / S D=1,977, G F I=0,903$, $\mathrm{AGFI}=0,872, \mathrm{CFI}=0,947, \mathrm{TLI}=0,937, \mathrm{IFI}=0,948, \mathrm{RMSEA}=0,051$ ).

Table 2: Results of path analysis

\begin{tabular}{|l|l|l|l|}
\hline Analysis & Coefficient & T-value & Result \\
\hline $\mathrm{H}^{1}$ Escape <--- Friend attachment &, 46 & 5,78 & Accept $^{* *}$ \\
\hline $\mathrm{H}^{2}$ Sociability <---Friend attachment &, 49 & 6,02 & Accept $^{* *}$ \\
\hline $\mathrm{H}^{3}$ Sociability <--- Escape &, 66 & 8,42 & Accept $^{* *}$ \\
\hline $\mathrm{H}^{4}$ Place attachment <--Sociability &, 77 & 13,33 & Accept $^{* *}$ \\
\hline $\mathrm{H}^{5}$ WOM<--- Place attachment &, 61 & 12,66 & Accept $^{* *}$ \\
\hline $\mathrm{H}^{6}$ Behavioral loyalty <--- Place attachment &, 31 & 7,34 & Accept $^{* *}$ \\
\hline $\mathrm{H}^{7}$ Behavioral loyalty <--- WOM &, 61 & 12,46 & Accept $^{* *}$ \\
\hline
\end{tabular}

Research hypotheses put forward within the context of the related literature have been tested and all hypotheses have been accepted. Friend attachment is an important predictor of escape $(\beta=, 49 ; p<0.01)$ and sociability $(\beta=, 66 ; p<0.01)$ structures. Similarly, the escape dimension was found to have a higher predictor of the sociability structure $(\beta=, 66$; $p<0.01)$. The sociability dimension was found to be very positively correlated with place attachment $(\beta=, 77 ; p<0.01)$. It has been determined that place attachment significantly affects both WOM $(\beta=, 61 ; p<0.01)$ and behavioral loyalty $(\beta$ $=, 31 ; p<0.01)$ structures. Finally, as predicted before, it was revealed in the research that fitness club members' WOM behavior was an important predictor of behavioral loyalty $(\beta=, 61 ; p<0.01)$.

\section{DISCUSSION}

Within the scope of the research, the effects of fitness club members' friend attachment, escape, place attachment and 
WOM behaviors on their loyalty were examined. Regarding the issue, Powers and Greenwell (2016) found that the number of fitness clubs is increasing rapidly every passing period $^{19}$. This situation led to the emergence of fitness clubs that appeal to different cultural and socio-economic levels within the sector. These developments brought competition at different levels within the industry. Especially determining factors affecting customer loyalty and taking the necessary precautions are vital for the sustainability of fitness facilities. In line with this information, it has been empirically proved that the structures considered in the study are the predictors of loyalty at different levels. In addition to the contributions made by the results, it provided important clues for the professionals in the industry. Different levels of positive relationships were determined between the sociability, escape and friend attachment structures tested in the context of the research. Veenhoven (2005) stated that the modern human being shaped by today's life conditions is in a stress cycle within a certain work routine ${ }^{20}$. This situation forces individuals to seek recreational activities to deal with stress. Danbert et al. (2014) stated that fitness clubs are the most popular places to meet this recreational need ${ }^{21}$. These results prove in parallel with the research results that escaping from the routine of daily life and participating in sports are very important factors in going to fitness clubs. Industry marketing practitioners need to consider these results and include them into their marketing strategies. Especially activities that increase the quality of interaction and the creation of an atmosphere that can evaluate the recreational time are very important at this point.

\section{CONCLUSION}

Based on the obtained results, it has been proven that there are strong relationships between fitness center customers' place attachment, WOM and loyalty structures. Lee et al. (2012) found that place attachment is an important predictor of WOM behavior and place attachment is essential for loyalty by does not make sense by itself ${ }^{18}$. In this case, it was stated that the factors related to place attachment should be determined. It is important to use more complex multivariate analytical methods (structural equation modeling) to understand the variance described among the related structures. In the context of the research, the sociability, escape and friend attachment structures associated with place attachment have been determined with SEM. This structure is very important in terms of its contribution to the existing space in the related literature. So, it was found that the satisfactory social experiences (escape, sociability and friend attachment) of the fitness center members reveal positive attitudes (WOM behavior) and behavioral loyalty with the mediating effect of place attachment. It can be stated in the context of our research that the loyalty process in fitness centers can not only be provided by service quality, but also from existing physical (eg environment, location character and attraction) and social factors (eg customer profile and service personnel). Thus, in order to develop loyalty, it is very important for marketers to realize creative innovations for spatial and social contexts in which sports are performed in terms of their target mass.

As in all studies conducted, this study has a number of limitations arising from the process and scope, apart from methodological constraints, and suggestions for future research in this context. This research was carried out by convenience sampling method, which is one of the nonprobability sampling methods, so more generalizable results can be obtained from the planned studies with the probability sampling method. This research was carried out in line with the principles of quantitative research methodologies. In researches benefit from qualitative research methodologies more in-depth data can be obtained. Within the scope of the research, only fitness clubs operating in Eskişehir have been reached. In this direction, different results can be obtained from the researches that will be carried out for different fitness clubs in different cities. Conducting research covering different cultures will be important in revealing the cross-cultural differentiation of fitness club members. Finally, new models for the phenomena that affect the loyalty levels of fitness center members can be identified with different variables supported in the light of the literature.

\section{REFERENCES}

1. Schiffman, Jason, and Eric L. Daleiden. Population and service characteristics of youth with schizophrenia-spectrum diagnoses in the Hawaii system of care. Journal of Child Psychology and Psychiatry 2006;47(1): 58-62.

2. Funk, Daniel C., Anthony Beaton, and Kostas Alexandris. Sport consumer motivation: Autonomy and control orientations that regulate fan behaviours. Sport management review 2012; 15(3): 355-367.

3. Manzo, Lynne C. "Beyond house and haven: Toward a revisioning of emotional relationships with places." Journal of environmental psychology, 2003; 23(1): 47-61.

4. Williams, DR., Patterson, M.E., Roggenbuck, JW. andWatson, A. E. Beyond the commodity metaphor: Examining emotional and symbolic attachment to place. Leisure sciences 1992; 14(1): 29-46.

5. Prayag, Girish, and Chris Ryan. Antecedents of tourists' loyalty to Mauritius: The role and influence of destination image, place attachment, personal involvement, and satisfaction. Journal of travel research 2012; 51(3): 342-356.

6. Williams, Daniel R., and Jerry J. Vaske. The measurement of place attachment: Validity and generalizability of a psychometric approach. Forest science 2003; 49(6): 830840.

7. Segrave, Jeffrey O. Sport as escape. Journal of Sport and Social Issues 2000; 24(1): 61-77.

8. Melnick, Merrill J. Searching for sociability in the stands: A theory of sports spectating. Journal of sport Management 1993; 7(1): 44-60.

9. Gau, Li-Shiue, and Felipe Korzenny. An examination of values associated with sports attitude and consumption behavior: An exploratory study. Social Behavior and Personality: an international journal 2009; 37(3): 299-305.

10. Milligan, Melinda J. Interactional past and potential: The social construction of place attachment. Symbolic interaction 1998, 21(1): 1-33.

11. Hidalgo, M. Carmen, and Bernardo Hernandez. Place attachment: Conceptual and empirical questions. Journal of environmental psychology 2001; 21(3): 273-281.

12. Harrison-Walker, L. Jean. The measurement of word-ofmouth communication and an investigation of service quality and customer commitment as potential antecedents. Journal of service research $2001 ; 4(1): 60-75$.

13. Bergami, Massimo, and Richard P. Bagozzi. Self-categorization, affective commitment and group self-esteem as distinct aspects of social identity in the 
organization. British journal of social psychology 2000; 39(4): 555-577.

14. Kyle, Gerard, Alan Graefe, and Robert Manning. Testing the dimensionality of place attachment in recreational settings. Environment and behavior 2005; 37(2): 153-177.

15. Branscombe, Nyla R., and Daniel L. Wann. The positive social and self concept consequences of sports team identification. Journal of Sport and Social Issues 1991;15(2): 115-127.

16. Samson, Alain. Product usage and firm-generated word of mouth: Some results from FMCG product trials. International Journal of Market Research 2010; 52(4): 459-482.

17. Neale, Larry, and Daniel Funk. Investigating motivation, attitudinal loyalty and attendance behaviour with fans of Australian football. International Journal of Sports Marketing and Sponsorship 2006; 7(4): 12-22.

18. Lee, Jenny, Gerard Kyle, and David Scott. "The mediating effect of place attachment on the relationship between festival satisfaction and loyalty to the festival hosting destination." Journal of travel research 2012; 51(6): 754-767.

19. Greenwell, D. Powers D. Branded fitness: Exercise and promotional culture. Journal of Consumer Culture161 1 (2016): 19.

20. Veenhoven, Ruut. Return of inequality in modern society? Test by dispersion of life-satisfaction across time and nations. Journal of Happiness Studies 2005; 6(4): 457-487.

21. Danbert, Samantha J., et al. Academic success and retention: The role of recreational sports fitness facilities. Recreational Sports Journal 2014; 38(1): 14-22.

22. Yavuz Eroğlu, S. \& Eroğlu, E. (2020). Adaption of the Spectator-Based Sports Team Reputation into Turkish: A Validity And Reliability Study, International Journal of Eurasian Education and Culture, Issue: 10, pp. (1704-1721). 